\title{
Preparation of an Electrochemical Sensor for Rapid Detection of Lead(II) in Blueberries
}

\author{
Hong $\mathrm{Wu}^{1, *}$, Sainan Qiao $^{2}$, Ning Zhang ${ }^{2}$ and Yali Zhang ${ }^{1}$ \\ ${ }^{1}$ College of Tourism and Hotel Management, Shanxi Technology and Business College, Taiyuan, \\ Shanxi, 030000 China \\ ${ }^{2}$ Department of Nursing and Health Management, Shijiazhuang Vocational College of Finance \& \\ Economics, Shijiazhuang, Hebei, 050061, China \\ *E-mail: hongwu_197778@163.com
}

doi: $10.20964 / 2021.08 .46$

Received: 15 April 2021 / Accepted: 4 June 2021 / Published: 30 June 2021

Blueberries tend to accumulate lead ions in the plant tissue for the reason that they are grown in acidic soil. The detection of lead ions in blueberries is a very important research objective in the field of food safety. In this work, a highly fast technique for electrochemical analysis was proposed. Nitrogen-doped carbon nanospheres were synthesized for the surface modification of glassy carbon electrodes, and the modified electrodes exhibited a sensitive response to lead ions. By optimizing the potential increments, pulse amplitude, pulse width, accumulation potential and accumulation time, this method can detect lead ions in the range of $10 \mathrm{nM}-4 \mu \mathrm{M}$ with the detection limit calculated to be $1.05 \mathrm{nM}$. In addition, the proposed electrochemical analysis has been successfully adopted to detect lead ions in blueberry samples.

Keywords: Lead ions; Electrochemical sensor; Analytical method; Blueberry; Nitrogen-doped carbon sphere

\section{FULL TEXT}

(C) 2021 The Authors. Published by ESG (www.electrochemsci.org). This article is an open access article distributed under the terms and conditions of the Creative Commons Attribution license (http://creativecommons.org/licenses/by/4.0/). 